\title{
SELF-INVERSIVE MATRIX POLYNOMIALS WITH SEMISIMPLE SPECTRUM ON THE UNIT CIRCLE
}

\author{
NAOHARU ITO, REINHOLd KÜSTNER AND HARALD K. WimmER
}

Abstract. The spectrum of a class of self-inversive matrix polynomials is studied. It is shown that the characteristic values are semisimple and lie on the unit circle if the inner radius of an associated matrix polynomial is greater than 1 .

Mathematics subject classification (2010): 15A33, 15A24, 15A57, 26C10, 30C15, 39A11.

Keywords and phrases: Self-inversive polynomials, zeros of polynomials, matrix polynomials, numerical range, inner radius, semisimple characteristic values, normal characteristic values, Eneström-Kakeya theorem, system of linear difference equations.

\section{REFERENCES}

[1] B. AdHIKARI And R. Alam, Structured backward errors and pseudospectra of structured matrix pencils, SIAM J. Matrix Anal. Appl., 31 (2009), 331-359.

[2] H. Baumgärtel, Analytic Perturbation Theory for Matrices and Operators, Operator Theory, Advances and Applications, Vol. 15, Birkhäuser, Basel, 1985.

[3] Y. Bistritz, A circular stability test for general polynomials, Systems Control Lett., 7 (1986), 89-97.

[4] E. Bogomolny, O. Bohigas, And P. LeBoeuf, Quantum chaotic dynamics and random polynomials, J. Statistical Physics, 85 (1996), 639-679.

[5] P. Borwein And T. Erdèly, Polynomials and Polynomial Inequalities, Springer, New York, 1995.

[6] R. Byers, D. S. Mackey, V. Mehrmann, And H. XU, Symplectic, BVD, and palindromic approaches to discrete-time control problems, in P. Petkov and N. Christov, editors, A Collection of Papers Dedicated to the 60th Anniversary of Mihail Konstantinov, pp. 81-102, Sofia, 2009, Publ. House Rodina. http: //eprints.ma.man.ac.uk/1062/01/ByeMMX08_ppt-final_26-03-2008_00-2649.pdf

[7] K. CHInEn, An abundance of polynomials satisfying the Riemann hypothesis, Discrete Math., 308 (2008), 6426-6440.

[8] M. Dahlby And B. OWren, Plane wave stability of some conservative schemes for the cubic Schrödinger equation, ESAIM: M2AN, 43 (2009), 677-687.

[9] G. DiRr AND H. K. Wimmer, An Eneström-Kakeya theorem for hermitian polynomial matrices, IEEE Trans. Automat. Control, 52 (2007), 2151-2153.

[10] I. Gohberg, P. Lancaster And L. Rodman, Matrix Polynomials, Academic Press, New York, 1982.

[11] A. Hilliges, Numerische Lösung von quadratischen Eigenwertproblemen mit Anwendung in der Schienendynamik, Diplomarbeit, TU Berlin, Institut f. Mathematik, 2004.

[12] B. IANNAZZO AND B. MeINI, Palindromic matrix polynomials, matrix functions and integral representations, Linear Algebra Appl., 434 (2011), 174-184.

[13] M. Jibladze And D. Novikov, Unimodularity of Poincaré polynomials of Lie algebras for semisimple singularities, Moscow Math. J., 7 (2007), 481-487.

[14] D. KRESSNER, CH. SChroeder, AND D. S. WATKInS, Implicit QR algorithms for palindromic and even eigenvalue problems, Numer. Algorithms, 51 (2009), 209-238.

[15] P. Lakatos, On polynomials with zeros on the unit circle, C. R. Math. Acad. Sci. Soc. R. Can., 24 (2002), 91-96. 
[16] P. Lakatos And L. Losonczi, Polynomials with all zeros on the unit circle, Acta Math. Hung., 125 (2009), 341-356.

[17] CH.-K. Li And L. Rodman, Numerical range of matrix polynomials, SIAM J. Matrix Anal. Appl., 15 (1994), 1256-1265.

[18] D. St. Mackey, N. Mackey, Ch. Mehl, And V. Mehrmann, Structured polynomial eigenvalue problems: good vibrations from good linearizations, SIAM J. Matrix Anal. Appl., 28 (2006), 10291051.

[19] D. St. Mackey, N. Mackey, Ch. Mehl, and V. Mehrmann, Numerical methods for palindromic eigenvalue problems: Computing the anti-triangular Schur form, Numer. Linear Algebra Appl., 16 (2009), 63-86.

[20] D. St. Mackey, N. Mackey, Ch. Mehl, and V. Mehrmann, Smith forms of palindromic matrix polynomials, Electron. J. Linear Algebra, 22 (2011), 53-91.

[21] M. Marden, Geometry of Polynomials, 3rd ed., Mathematical Surveys No. 3, Amer. Math. Soc., Providence, RI, 1966.

[22] I. Markovsky AND S. Rao, Palindromic polynomials, time-reversible systems, and conserved quantities, in: 16th Mediterranean Conference on Control and Automation, 2008, Ajaccio. http://eprints.ecs.soton.ac.uk/16592/1/Med08.pdf

[23] Q. I. Rahman and G. SchmeIsser, Analytic Theory of Polynomials, Oxford University Press, Oxford, 2002.

[24] L. RoDman, Bounded and stably bounded palindromic difference equations of first order, Electron. J. Linear Algebra, 15 (2006), 22-49.

[25] J. SCHUR, Über Potenzreihen, die im Innern des Einheitskreises beschränkt sind, J. reine angew. Math., 147 (1917), 205-232.

[26] T. Sheil-Small, Complex Polynomials, Cambridge University Press, Cambridge, 2002.

[27] Сн. Sкокоs, On the stability of periodic orbits of high dimensional autonomous Hamiltonian systems, Physica D, 159 (2001), 155-179.

[28] J. Y. Stein, Digital Signal Processing: A Computer Science Perspective, Wiley Series in Telecommunications and Signal Processing, Wiley, 2000.

[29] P. Stoica And R. L. Moses, On the unit circle problem: The Schur-Cohn procedure revisited, Signal Processing, 26 (1992), 95-118.

[30] A. P. Velo, G. A. Gazonas, And T. Ameya, z-Transform methods for the optimal design of one-dimensional layered elastic media, SIAM J. Appl. Math. 70, 3 (2009), 762-788. 